\title{
Memory Skills: Whose Concern?
}

\section{David Fraser}

Educators are now concerned that modern generations of students are not yet prepared with the memory skills for processing aural and visual information, let alone the information contained in books. Research on various memory skills when tried with various media may reveal effective ways to transfer not only fleeting aural and visual information but the time-honored printed word as well. The question is, "Which strategies are the most effective in processing which media?" Since a great deal of memorizing takes place in libraries, librarians are in a good position to study this question and, perhaps, to contribute to what little is known about the effectiveness of individual memory strategies during the transfer process. The author suggests that librarians extend their interests beyond material and electronic processing to include the processing of information in human memory.

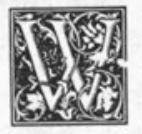

ho should be undertaking scientific research on memory skills? First of all, who might be helped by the results of such research? Students and professional scholars, of course, ought to be helped by the results. Findings may suggest new and improved ways to present, study, and mentally process information. Whose concern is it, then, to conduct the research that might help people improve their mental information processing skills? Educators? Psychologists? Communications experts? Yes, all of them, and one more group-librarians. Why librarians?

Traditionally librarians are seen in our society as responsible for material information processing, even though admittedly we do little more than store and retrieve information. ${ }^{1}$ Yet, despite the outward success of librarians in the practice of information processing, the profession has been roundly criticized over the years as lacking in theories of processing. ${ }^{2}$ In answer to this criticism, scholar Manfred Kochen has maintained that "a new intellectual discipline seems to be in the making: it is the study of processes by which knowledge grows. ${ }^{\prime 3-}$ Regrettably, this engaging concept has not been articulated much beyond the suggestion that it is "concerned with the lawful regularities governing the acquisition of information and its transformation into knowledge.",4 Kochen has called this fledgling discipline "Epistodynamics," presumedly, "ways of knowing." Another prominent thinker, Jesse Shera, caught a glimpse of the same concept when he introduced his theory of "Social Epistemology," which has as its focus "the production, flow, integration, and consumption of all forms of communicated thought.,"5 Not until the recent emergence of "The Information Society," have academicians recognized that the information professions are based upon a concrete body of theory, albeit one shared by other disciplines. This body of theory consists of what we know (and have yet to find out) about the various processes information undergoes, including its initial expression, its presentation through diverse media, its physical and intellectual control, its dissemination and accessibility, its comprehension by the curious, its acquisition and retention in hu-

David Fraser is librarian of the Historical Society of Pennsylvania, Philadelphia, Pennsylvania 19107. He is also a doctoral candidate in the School of Library Service at Columbia University. 
man memory, and its persistence over time. ${ }^{6}$ Theories about information processing, both material processing and mental processing, are the very bases not only of education, psychology, and communications but of librarianship and information science as well. Yet, while librarians seem versed in material processing (classifying, indexing, and searching), it is hard to imagine librarians as theorists in mental information processing-unless one considers the librarian's counseling function.

Counseling mental information processing, however, has long been thought the province of educators, psychologists, and communications experts. And with good reason. These practitioners boast good track records in helping people find ways to improve their abilities to process information. Educators, for instance, are presently raising questions about the effects of individual differences on the mental approach a person might bring to information processing tasks. ${ }^{7}$ Among psychologists today, fresh interest in the mysteries of the mind has fostered a new branch of investigation, one which unreservedly opens the "black boxes" of our brains to speculate how they work-how they acquire, organize, and process information, how they commit material to memory. ${ }^{8}$ Communications experts have long shown an interest in improving the processes by which information reaches people's memories. They are concerned that if the medium through which a particular message is presented turns out to be hard to process, the message may never reach its intended audience.' Are librarians also in a position to counsel people on ways to process information mentally? Are we librarians needed in the investigation of problems related to mental information processing?

Problems today may require "team" solutions. Concern over the flagging ability of today's students to process and retain information has led to studies of our educational system, particularly regarding its effectiveness in preparing students to cope in an "information society." Critic Neil Postman observes that "schools are still promoting the idea that the main source of wisdom is to be found in li- braries. ${ }^{10}$ From this assumption follows that the main medium for conveying wisdom is still the written word, and, further, that the main process for acquiring wisdom is still, of course, reading. Yet recent research indicates that the vast majority of young generations in this country demonstrate "very few skills for examining the nature of the ideas they take away from their reading," and investigators are urging educators to begin preparing students to function in a society where information and its management are linked to spoken and pictorial media as well. ${ }^{11}$ Most teachers, however, still seem to be convinced that literacy is the richest source of information, even in face of the fact that modern generations are spending billions of dollars a year on radios, records, and videos, and spending equal billions of hours in front of TV sets. Both formal surveys and casual observation confirm that enormous numbers of Americans today obtain their daily information not primarily from reading, but rather from tuning into the aural and visual sources of radio and television. ${ }^{12}$ In a given day, for example, most people devote from 42 to 48 percent of their time to listening and viewing, and only 10 to 15 percent to reading. ${ }^{13}$

If it is true that we modern generations obtain much of our information from sources other than printed media, then what skills do we have at our disposal for remembering aural and visual information? How do we learn to listen, and how do we learn to observe? Does today's student know how to "memorize" such information as might be contained in "that required 'Cosmos' episode on last night?" Many of us are seemingly so inept at aural and visual retention that we are unable to remember last night's TV program the following day-even if we wanted to. ${ }^{14}$ Each medium of communication, written, spoken, or pictorial, contains a unique metaphysic-each medium makes special kinds of claims on our senses and, therefore, on our various processing skills. ${ }^{15}$ If we were to discover what we do wrong in the listening and viewing processes, if we were to develop specific memory skills to strengthen our listening and viewing comprehension, perhaps then we would 
have a better chance of recalling last night's fleeting aural and visual information.

Reading itself, when one comes to think of it, is really an aural process. ${ }^{16}$ Most of us seem to deal with written information by speaking the words to ourselves internally as we read along. ${ }^{17}$ (Right now, if you are saying these very words silently to yourself, you are living proof that at least some of us subvocalize as we read.) So, since some of us convert the sight of a word to its corresponding sound before processing it, the act of reading should probably be studied as a form of listening. Perhaps our brains prefer to deal with the sounds of words (either sounds heard aloud or sounds reported silently), and may have difficulty processing written information from just the sights of words alone. ${ }^{18}$ Our memory for written information, then, might actually be aural memory! That this could be possible is the subject of continual debate, especially among teachers of elementary reading. ${ }^{19}$ Presently the swing between theories of early reading seems to be away from the "whole-word" sight method back towards the "letter-byletter" phonic method, so that listening skills are now being emphasized by some teachers more than visual recognition skills. ${ }^{20}$ Another instance of our apparent reliance on listening skills is the common phenomenon of near-deaf persons' speaking loudly. Perhaps they do so not because they think others are unable to hear, but rather because they have trouble listening to their own voices. Carrying this line of speculation further, if we do not possess strategies for listening to what our subvocal voices recite as we scan the printed page (if we are in fact capable of reading and listening at the same time), our chances of remembering what we have read may be very slim indeed.

There must be ways to form durable remembrances of information even when it is only quickly read or momentarily heard or seen. By designing experiments to test the effectiveness of various strategies for processing various media, we may strike upon new models for mastering information, not only when it is presented through written texts, but also when it ap- pears in the increasingly popular, but inherently ephemeral, spoken and pictorial forms.

One approach to exploring how people might create "durable remembrances of information" whether presented in writing, speech, or picture, is to review what we know about the development of memory and to rethink the basic principles of successful memorization. What is it that makes a piece of information "stick" in memory? How does one go about developing "a well-stocked mind?" Too often we hear college graduates say they wish they could go back to school. They say that with what they know now, they would get more out of college. What do they know now that they didn't know before? One explanation is they simply know more about how their memory works. ${ }^{21}$ Perhaps over the years they have acquired a variety of memory techniques and strategies that had not occurred to them earlier in life. Psychologists say that "the main difference between young children and mature memorizers is the tendency to employ a variety of mnemonic strategies whenever feasible. ${ }^{\prime 22}$ When most of us are confronted by the task of studying and memorizing an entirely new piece of information-for instance an historical event, or a scientific formula, or the elements of a literary plot-we apparently either search in prior memory for something similar with which to associate the new information, or we concoct some kind of memory strategy, verbal or visual, clever or mundane, by which that unfamiliar new material can not only be initially processed, but be "permanently" retained and readily recalled. ${ }^{23}$ Mature learners realize how to improve memory by linking new information to old information already stored in long-term memory. ${ }^{24}$ Quite simply, they have developed what Alfred Binet (of Stanford-Binet-aptitudetest fame) calls "mnemonic virtuosity." A person who has built a repertory of mnemonic strategies can probably memorize information faster and remember it longer than a person to whom the thought of using memory strategies has never occurred. And it stands to reason that certain memory strategies might work better 
than others in memorizing information from certain kinds of media. That these simple but intriguing phenomena may be true is a presumption requiring investigation.

"No two people think alike." This may be just another way of saying not everyone approaches the acquisition of information in quite the same way. We all seem to have our own processing preferences and rely on those preferred ways out of habit. ${ }^{25}$ Persons who can readily process everything they read, for example, may have difficulty processing information they either hear or observe. And vice versa. Are the memory strategies we employ for processing textual information the same ones we should actively use when we want to remember what is being said in an important meeting or to recall the images we are watching in a special TV program? When we set out to commit material to memory, what are the memory strategies we might apply to the challenge? Do some strategies work for us individually while other strategies fail? Could there, in fact, be certain "right" types of memory strategies that would be particularly effective for us when matched to particular media-one group of strategies, perhaps, for verbal media and another type for pictorial media? If so, can these "right strategies" be articulated and classified for discussion and testing?

More importantly, why is it that, even when we think to employ memory strategies, not all of us experience improved memory performance? ${ }^{26}$ Could it be we sometimes select an inappropriate memory strategy for the medium at hand? Can our information processing abilities be enhanced, perhaps, by our knowing which memory strategy to employ for the particular medium we are faced with? For example, when it comes to written media, one person may read a paragraph of text and vocalize the material either aloud or silently, thereby fixing the information in mind as a series of mental phonemes. This act of rehearsing is still the most common strategy for rote memory work from written media. ${ }^{27}$ A second person may read the same information and choose instead to visualize pictures from the written mate- rial in order to represent them in memory as a series of mental images. ${ }^{28}$ Many artists report a facility for creating mental pictures from words. A third person might process the same information by forming images of the words and sentences themselves. This seems to be a popular choice of speed-readers, note takers, and people with "photographic memories. ${ }^{\prime 29}$ If the target information were to have been presented through either a spoken or pictorial medium rather than a written one, the choice between processing strategies, either vocalizing or visualizing, would have been the same. The key question is worth repeating: "Which set of strategies, vocalization or visualization, might be the most effective for the medium at hand?"

Discovering the whole answer, if there is one, would involve isolating and testing all the independent variables that affect human cognition and memorization, including not only various memory strategies and media, but also variations in the meaningfulness of target information, differences in sensory astuteness from one individual to another, the influence of settings other than the laboratory, and the choices resulting simply from personal preferences. Isolating two sets of variables, "different kinds of memory strategies" and "different kinds of media," however, may be a good way to begin.

Perhaps the first step in investigating the relationships between memory strategies and media would be to explore people's memorizing behavior while they are in the process of mastering information from different modes of presentation. The hope would be to identify unusual strategies of individual invention (which might later be classified into distinct categories along with strategies already known). Then we might test these categories of memory strategies in experiments designed to determine their relative effectiveness on human memory when information is presented through various written, spoken, and pictorial forms. The significance of this kind of research lies in the chance we might discover which combinations of memory strategy and medium facilitate the transfer of information into memory and prolong its retention 
there. Correlations of memory strategies with media could point up unusually effective processing combinations, or what might be called "distinctive styles of studying." For example, one style of studying might be to apply a visualization strategy in memorizing information from a written medium. Another possibility would be to employ a vocalization strategy with certain pictorial media. And so on. Our eventual ability to recommend alternative styles of studying to individual learners promises to give new importance to the counseling of study habits.

Still, what does all this have to do with librarians? Some library educators have realized that counseling study habits is one of the fundamental concerns of the profession. ${ }^{30}$ This impression has been substantiated by research in the field.$^{31} \mathrm{~A}$ recent survey conducted at Haverford College, for example, shows that the library there functions primarily as a study hall! ${ }^{32}$ Of the 761 users in the Haverford sample, 425 entered the library for the express purpose of studying their own books. This should come as no surprise. After all, scholarship begins with study and memory work, and libraries are generally conducive surroundings for those purposes. The use of libraries for memory work has gradually placed a special educational responsibility on librarians-that of "tutor" or "learners' advisor.,"33

Why should we librarians be concerned about the development of memory skills? Research on memory skills involves asking not so much about how the mind works (this question is being addressed by cognitive scientists), but rather about what makes the mind work, a question for information scientists. Call it "epistodynamics," or "social epistemology," or "information science," we librarians should be as much concerned about people's abilities to process information as we are about people's abilities to find it, especially if we intend to tutor and advise learners on their approaches to studying. If we are to help people develop effective study skills, we too should join in the research on human information processing and experiment with various vocalization and visualization memory strategies ourselves. $^{34}$

In a larger sense, if information professionals are able to teach students how to try different memory strategies with different media on their own until they strike upon the most effective combinations for themselves in particular, then at least we shall have helped them become aware of the range of studying styles at their disposal. Perhaps if they reach this stage of self-awareness they will be demonstrating the very skills our nation's educational watchdogs sense are necessary for "examining the nature of ideas," whether those ideas come from books or from the more popular media of radio and television.

\section{REFERENCES}

1. Vincent E. Giuliano, "Manifesto for Librarians," Library Journal 104:1837-42 (Sept. 15, 1979); Forest W. Horton, 'Emerging Information Counselor: A New Career Path in Need of a Champion,' ASIS Bulletin 8:16-19 (June 1982).

2. Charles C. Williamson, Training for Library Service (New York: Carnegie Corporation, 1923); William J. Goode, "The Librarian: From Occupation to Profession?," Library Quarterly 31:306-20 (Oct. 1961); Abraham Kaplan, "The Age of the Symbol-A Philosophy of Library Education," in Recurring Library Issues: A Reader, ed. C. M. Coughlin (Metuchen, N.J.: Scarecrow, 1979); Ralph W. Conant, The Conant Report: A Study of the Education of Librarians (Cambridge, Mass.: MIT Pr., 1980).

3. Manfred Kochen, "Stability in the Growth of Knowledge," American Documentation 20:186 (July 1969).

4. Ibid., p.195.

5. Jesse Shera, Foundations of Education for Librarianship (New York: Becker and Hayes, 1972), p.112.

6. Herman M. McLuhan and others, "Understanding Media," mimeographed (Washington, D.C.: U.S. Office of Education, 1960); Carl Sagan, Cosmos (New York: Random, 1980); Alvin Toffler, The Third Wave (New York: Morrow, 1980); Morton Hunt, The Universe Within: A New Science Explores the Human Mind (New York: Simon \& Schuster, 1982); Michael Edelhardt, "Immortality through Science?" Psychology Today 17:40-41 (Aug. 1983). 
7. Rita Dunn and Kenneth Dunn, Teaching Students Through Their Individual Learning Styles: A Practical Approach (Reston, Va.: Reston, 1978).

8. Hunt, The Universe Within.

9. Jerry C. Olson, "Theories of Information Encoding and Storage: Implications for Consumer Behavior," in The Effect of Information on Consumer and Market Behavior, ed. Andrew A. Mitchell (Chicago, Ill.: American Marketing Assn., 1978); James R. Bettman, An Information Processing Theory of Consumer Choice (Reading, Mass.: Addison-Wesley, 1979); Gabriel Biehal and Dipankar Chakravarti, "Information-Presentation Format and Learning Goals as Determinants of Consumer's Memory Retrieval and Choice Processes," Journal of Consumer Research 8:431-41 (Mar. 1982).

10. Neil Postman, "The Politics of Reading," Harvard Educational Review 40:250 (May 1970).

11. United States Department of Education, Report of the Commission on National Assessment of Educational Progress (Washington, D.C.: U.S. Office of Education, 1981); National Commission on Excellence in Education, A Nation at Risk: The Imperative for Educational Reform (Washington: Govt. Print. Off., 1983).

12. Herman M. McLuhan, The Gutenberg Galaxy: The Making of Typographic Man (Toronto, Canada: Univ. of Toronto Pr., 1962); McLuhan, Understanding Media: The Extensions of Man (New York: McGraw-Hill, 1964); Toffler, Third Wave; Louis Forsdale, Perspectives on Communication (Reading, Mass.: Addison-Wesley, 1981); John Naisbitt, Megatrends (New York: Warner, 1984).

13. P. Rankin, "Listening Ability," in Proceedings of the Ohio State Educational Conference's Ninth Annual Session (Columbus, Ohio: Ohio State Univ., 1929); D. Bird, "Teaching Listening Comprehension," Journal of Communication 3:127-30 (1953); L. Breiter, "Research in Listening and Its Importance to Literature"' (Master's Thesis, Brooklyn College, 1957).

14. H. A. Anderson, "Needed Research in Listening," in Listening Readings, ed. Samuel Duker (New York: Scarecrow, 1966).

15. McLuhan, Understanding Media; Postman, "Politics."

16. William P. Banks, Evelyn Oka, and Sherrie Shugarman, "Recoding of Printed Words to Internal Speech: Does Recoding Come Before Lexical Access?"' in Perception of Print: Reading Research in Experimental Psychology, ed. Ovid J. L. Tzeng and Harry Singer (Hillsdale, N.J.: Erlbaum, 1981).

17. George Sperling, "Phonemic Model of Short Term Auditory Memory," Proceedings of the 76th Annual Convention of the American Psychological Association, 1968 3:63-64; David A. Walter, "The Role of Phonemic and Semantic Dimensions of Memory in Sentence Memory and Comprehension" (Ph.D. diss., Univ. of Michigan, 1973).

18. Roger Brown, "Psychology and Reading," in Basic Studies On Reading, ed. H. Levin and J. P. Williams (New York: Basic Books, 1970), p.178.

19. Jeanne S. Chall, Learning to Read: The Great Debate (New York: McGraw-Hill, 1967; James R. Layton, The Psychology of Learning to Read (New York: Academic, 1979); Lauren B. Resnick and Phyllis A. Weaver, Theory and Practice of Early Reading (Hillsdale, N.J.: Erlbaum, 1979).

20. Rudolf Flesch, Why Johnny Can't Read-And What You Can Do About It (New York: Harper, 1955; Flesch, Why Johnny Still Can't Read (New York: Harper, 1981).

21. Ann L. Brown, "The Development of Memory: Knowing, Knowing about Knowing, and Knowing How to Know," in Advances in Child Development and Behavior, 10, ed. H. W. Reese (New York: Academic, 1975); John H. Flavell and H. M. Wellman, "Metamemory," in Perspectives on the Development of Memory and Cognition, ed. R. V. Kail, Jr., and W. Hagen (New York: Wiley, 1977).

22. Ann L. Brown and J. DeLoache, "Skills, Plans, and Self-Regulation," in Children's Thinking: What Develops?, ed. R. Siegler (Hillsdale, N.J.: Erlbaum, 1978), p.5.

23. John E. Harris, "External Memory Aids," in Practical Aspects of Memory, ed. M. M. Gruneberg and others (London: Academic, 1978).

24. Allan M. Collins and M. Ross Quillian, "Retrieval Time from Semantic Memory," Journal of Verbal Learning and Verbal Behavior 8:240-47 (Apr. 1969); John R. Anderson and Gordon H. Bower, "The Structure of Knowledge," in Human Associative Memory, eds. Anderson and Bower (New York: V. H. Winston, 1973); Eleanor Rosch and Carolyn B. Mervis, "Family Resemblances: Studies in the Internal Structure of Categories," Cognitive Psychology 7:573-605 (Oct. 1975).

25. Richard Bandler and John Grinder, Frogs into Princes (Moab, Utah: Real People Pr., 1979).

26. Flavell and Wellman, "Metamemory"; Brown and De Loache, "Skills."

27. Richard C. Atkinson and R. M. Shiffrin, "Human Memory: A Proposed System and Its Control Processes," in The Psychology of Learning and Motivation: Advances in Research and Theory, 2, ed. K. W. Spence and J. T. Spence (New York: Academic, 1968); William K. Estes, "Phonemic Coding and Rehearsal in Short-Term Memory for Letter Strings," Journal of Verbal Learning and Verbal Behavior 12:360-72 (Aug. 1973).

28. Geir Kaufmann, Visual Imagery and Its Relation to Problem Solving: A Theoretical and Experimental In- 
quiry (Bergen, Norway: Universitesforlaget, 1979); Stephen M. Kosslyn, Image and Mind (Cambridge, Mass.: Harvard Univ., 1980).

29. Norma E. Cutts and Nicholas Moseley, "Notes on Photographic Memory," Journal of Psychology 71:3-15 (Jan. 1969).

30. Louis Shores, "The Library Arts College, a Possibility in 1954?," School and Society 41:110-14 (1935); "The Library College Idea," Library Journal 91:3871-75(Sept. 1, 1966); Daniel P. Bergen and Edwin D. Duryea, eds., Libraries and the College Climate of Learning (Syracuse, N.Y.: Syracuse Univ., 1964); Martha Maxwell, Improving Student Learning Skills (San Francisco, Calif.: Jossey-Bass, 1979).

31. Patricia B. Knapp, The Monteith College Library Experiment (New York: Scarecrow, 1966); F. L. Christ, "Systems for Learning Assistance: Learners, Learning Facilitators, and Learning Centers, " in Interdisciplinary Aspects of Reading Instruction, ed. F. L. Christ (Proceedings of the 4th Annual Conference of the Western Reading Association, 1971); Gary T. Peterson, The Learning Center: A Sphere for Nontraditional Approaches to Education (Hamden, Conn.: Linnet Books, 1975); Beverly P. Lynch, "The Changing Environment of Academic Libraries," College \& Research Libraries 39:10-14 (Jan. 1978).

32. Haverford College, Library Evaluation Document (Haverford, Pa.: Haverford College Library, 1980).

33. Norman W. Beswick, "Librarians and Tutor-Librarians," Library-College Journal 2:12-23 (Jan. 1969).

34. Stephen Monsell, "'Representations, Processes, Memory Mechanisms: The Basic Components of Cognition," Journal of the American Society for Information Science 32:378-90 (Sept. 1981); Suzanne E. Najarian, "Organizational Factors in Human Memory," Library Quarterly 51:269-91 (July 1981); Leigh S. Estabrook, "Human Dimension of the Catalog: Concepts and Constraints in Information Seeking," Library Resources \& Technical Services, 27:68-75 (Jan. 1983). 